\title{
Carne y nada más: la configuración del discurso cárnico en La Carne de René de Virgilio Piñera*
}

Fecha de recepción: 30 de agosto de 2016

Fecha de aprobación: 30 de abril de 2017

\section{Resumen}

Este artículo hace un análisis de la novela La carne de René, del escritor cubano Virgilio Piñera, desde la construcción del discurso hegemónico -al que llamo cárnico- el cual construye y define los cuerpos de los personajes y, por tanto, sus subjetividades. Así, este trabajo se pregunta por los mecanismos discursivos (como la parodia y las luchas entre poder-conocimiento sobre el cuerpo) que configuran el discurso cárnico y cómo este opera en los individuos de este universo literario (especialmente en René, su protagonista) para que puedan entenderse como sujetos constituidos de solo carne dispuesta al dolor, sin posibilidad de hacerse una vida espiritual. René, a pesar de ejercer resistencia al discurso cárnico, sucumbe ante este, ya que no logra hacerse una individualidad que esté por fuera del discurso, por lo que no le queda más remedio que aceptar que es un ser hecho de carne y nada más.

Palabras clave: carne, cuerpo, discurso, La carne de René, Virgilio Piñera.

Citar: Mora Moreno, S. A. (enero-junio de 2017). Carne y nada más: la configuración del discurso cárnico en La Carne de René de Virgilio Piñera. La Palabra, (30), 243 - 259. doi: https://doi.org/10.19053/01218530.n30.2017.6203

\section{Sergio Antonio Mora Moreno}

Docente Departamento de Lenguaje e Idiomas Extranjeros de la Universidad Santiago de Cali. Magíster en Literatura de la Universidad de los Andes. Profesional en Estudios Literarios de la Pontificia Universidad Javeriana, Bogotá.

sergio.mora00@usc.edu.co

* Artículo de reflexión producto de la tesis de investigación para obtener el grado de Magíster en Literatura de la Universidad de los Andes. 


\section{la palabra}

\section{Flesh and Nothing More: Configuration of Fleshed Discourse in La carne de René [Rene's Flesh] by Virgilio Piñera}

\section{Abstract}

This article analyzes the novel La carne de René [Rene's Flesh] by the Cuban writer Virgilio Piñera, from point of view of the construction of the hegemonic discourse - that I call "fleshed"- which builds and defines the bodies of its characters and their subjectivities. This paper, then, inquires into the discursive mechanisms (such as parody and the struggles between power-knowledge about the body) that constitute the flesh discourse and how it operates in the individuals of this literary universe (especially in René, the protagonist), so that they can be understood as subjects made up of mere flesh subjected to pain, and therefore unable to build a spiritual life. Despite exercising resistance to the flesh discourse, René succumbs to it, failing to propose an individuality beyond this discourse. Because of this, he has no choice but to accept that he is a being made of flesh and nothing more.

Keywords: Flesh, Body, Discourse, La carne de René [Rene's flesh], Virgilio Piñera

\section{La chair et rien de plus : la configuration du discours de la chair dans La carne de René [La Chair de René] de Virgilio Piñera}

\section{Résumé}

Dans cet article nous analyserons le roman La Chair de René de l'écrivain cubain Virgilio Piñera, à partir de la construction du discours hégémonique -que nous appelons discours de la chair- qui construit et définit les corps des personnages et, ainsi, leurs subjectivités. On analysera les mécanismes discursifs (comme la parodie et les luttes entre pouvoir-connaissance du corps) qui configurent le discours de la chair. Nous nous interrogerons sur la manière comme ce discours est mis en oeuvre parmi les individus de cet univers littéraire (spécifiquement chez René, le personnage principal). Nous nous demanderons si ce discours permet de comprendre les personnages comme sujets constitués uniquement d'une chair qui souffre, sans aucune possibilité de construire une vie spirituelle. En effet, même si René essaye de résister au discours de la chair, il finit par y succomber étant donné qu'il n'arrive pas à construire son individualité en dehors de celui-ci. De cette manière, il ne peut qu'accepter qu'il est constitué de chair et rien de plus.

Mots clés: chair, corps, discours, La Chair de René, Virgilio Piñera. 
La primera novela del escritor cubano Virgilio Piñera (19121979), La carne de René (2000), publicada en 1952 en la ciudad de Buenos Aires, construye un mundo donde gran parte de los individuos se entienden a sí mismos como carne, y para quienes el único fin de la vida es entregar su cuerpo al sufrimiento. El dolor, para estos sujetos, reafirma la idea de que somos nada más que un cuerpo, por lo que el martirio engrandece la vida al confirmar la condición corpórea. René, el personaje principal de esta novela, al ser un disidente en este mundo, busca construir formas de hacerse como individuo fuera de los dominios de la carne para no dar su cuerpo al servicio del dolor. Por lo tanto, para que los sujetos se entiendan a sí mismos como solo carne, hay un discurso que opera a través de un conocimiento que se construye sobre la misma.

Este discurso, el cual llamo cárnico, logra constituir los cuerpos de los sujetos en carne desde un aparato institucional que permite que el discurso circule y se imponga a los individuos como la única manera posible de ser en el mundo. Así, se entiende el cuerpo como un efecto de los discursos, en este caso, del discurso cárnico, el cual logra imponerse desde el entramado del poder a través de diversas estrategias y tácticas. Como lo señala Le Breton (2002), haciendo referencia a Foucault ${ }^{1}$, este, en Vigilar y castigar, "comprueba que las sociedades occidentales inscriben a sus miembros en las mallas cerradas de una red de relaciones que controla sus movimientos [...]. La disciplina extiende difusamente su ejercicio a través del campo social, apoyándose únicamente en aparatos represivos" (p. 84). De esta manera, el cuerpo es controlado y dispuesto por parte de las diversas instituciones, las cuales lo configuran a través de un discurso sobre el cuerpo.

Así, este artículo se centrará en el discurso, especialmente en cómo se configura el discurso cárnico en La carne de René (2000). Al realizar este análisis, también se podrá entender cómo dicho discurso opera en la novela, sobre todo en René, para lograr que este, después de una resistencia constante, se constituya como un sujeto dispuesto al dolor. A su vez, se examinará cómo la carne se convierte en la única extensión posible de la existencia ya que en La carne de René se elimina cualquier intento de trascendencia espiritual o, simplemente, de ser algo más que carne. Como lo plantea Quintero Herencia (2000), Piñera pone de manifiesto el cuerpo como la preocupación central de la novela ${ }^{2}$-la palabra "carne" aparece sistemáticamente para reiterar al lector que hay una esfera de la que no se puede escapar-, por lo que este es el lugar de disputa de conocimientos que configuran el sentido de la experiencia humana en la novela.

\section{La carne de René en disputa: la configuración del discurso cárnico}

La corporalidad que configura la novela no se limita a eliminar la esfera espiritual en la vida de los hombres, sino que busca transformar a los sujetos en carne, lo que implica que los individuos quedan desprovistos de cualquier forma de significación y de particularidad. Así, un ser humano puede ser equiparable a una res o a un perro. Según la lectura que hace Jorge Brioso (2007) de Oneself as Another, de Paul Ricoeur, plantea que:

Según Le Breton, Foucault (1972) se distancia de la crítica marxista, la cual señala que el control político de los cuerpos está en manos del aparato estatal. Para Foucault, el poder no se puede pensar como una propiedad que le pertenece a un único dueño (el Estado), sino que este es un sistema de relaciones que se despliega en diversas instituciones, las cuales ejercen el control y disciplina sobre los cuerpos.

2 Además de la importancia del estudio de Quintero Herencia (2000), esta aproximación a la obra está relacionado con el acercamiento crítico intertextual, en especial con los trabajos de Cámara (2002) y Anderson (2002), quienes proponen la parodia y la resignificación como elementos fundamentales para crear un nuevo sentido a partir de los elementos católicos presentes en La carné de René. 
La carne es esencialmente informe. No tiene género (un pedazo de carne está más allá de cualquier distinción sexual), no tiene individualidad (no se distingue de otros pedazos de carne y no pertenece a nadie). [...] Paul Ricoeur [...] hace mención de la distinción que establece Hussler entre Leib y Körper, entre carne y cuerpo. La carne sería, según esta distinción, esa zona anónima de nuestro cuerpo que compartimos con otros seres, que nos hace indiferenciables de los otros, el momento de mismidad en la otredad. (p. 44).

Este proceso de transformar los cuerpos en carne precisa de todo un armazón institucional, pedagógico y normativo para que el conocimiento sobre la carne pueda ser instruido, aprendido, regulado y vivido "espontáneamente". Como lo señala Corbin, Courtine y Vigarello (2005) en La historia del cuerpo:

El cuerpo [...] es a la vez receptáculo y actor frente a unas normas rápidamente ocultadas, interiorizadas, privatizadas, como ha demostrado Norbert Elias: lugar de un lento trabajo para reprimir y alejar lo impulsivo o espontáneo. De ello es buena prueba el esfuerzo por elaborar etiquetas, normas de educación y de control de uno mismo. (p. 20).

Dentro de estas instituciones que permiten que el discurso cárnico construya los cuerpos, está una escuela destinada a someter la carne a diferentes prácticas de tortura, las cuales tiene como propósito educar a los cuerpos para el servicio del dolor. De esta manera, los sujetos -al ser educados bajo ese conocimiento- no podrán entender su vida sin dar la carne a la flagelación y al martirio.

René tiene un destino en la novela: debe liderar la Causa, por lo que debe ser educado para logar someterse al discurso cárnico. La Causa es una institución de orden político que busca generar una revolución mundial por el chocolate, el cual ha sido un elemento de disputa por el poder desde tiempos atrás. Sin embargo, como se anuncia al final de la novela, el chocolate es solo una excusa para dar la carne al dolor para su propia destrucción.

A lo largo de la novela, René se rehúsa a seguir la ley del pa$\mathrm{dre}^{3} \mathrm{y}$, en ese sentido, niega su cuerpo a la Causa, por lo que debe estar en constante huida para no entregar su cuerpo a las sendas del dolor. Reinaldo Arenas (2002), en "La isla con todas sus cucarachas", relaciona la constante huida de René con las formas de resistencia de los marginados cubanos. Para Arenas, el esconderse, en el contexto cubano, es la forma de supervivencia por excelencia y, por la tanto, de resistencia. Así, en la obra de Piñera, personajes como René o Sebastián, de su novela Pequeñas maniobras, dan cuenta del sentido de supervivencia de ciertos sujetos cubanos, quienes deben huir del confin otorgado por las diversas instituciones sociopolíticas.

A pesar de su constante resistencia, René debe ocupar el lugar que le otorga su legado familiar paterno, el cual es reconocer su carne y la de los demás como carne dispuesta al dolor para estar a la cabeza de la Causa. Pero dicha tarea no es simple, puesto que el discurso que se teje sobre el cuerpo, en

Milda Žilinskaitè (2015), en su artículo “¿Qué tal? ¿Virgilio?’: apuntes sobre la relación intelectual entre Virgilio Piñera y Witold Gombrowicz", analiza cómo René busca romper con la estructura patriarcal al no seguir los designios de Ramón: "el padre representa los valores predominantemente machistas, mediatizados por las normas y tradiciones culturales" ( $p$. 78). Esto da cuenta de cómo Piñera busca alejarse de la idea del intelectual que debe edificar la nación desde su valores tradicionales, y se acerca al escritor crítico con su tiempo, lo cual se evidencia en la rebeldía de René hacia los sujetos y las estructuras sociales que edifican su mundo, como la escuela del dolor, la Causa y, por supuesto, su padre. De esta manera, Žilinskaitè señala que Piñera, con una obra como esta, va "contra una forzada alineación de la literatura a las identidades colectivas" (p. 77). 
el que instruyen y configuran la carne de René y la de los demás ciudadanos, se construye y se impone a lo largo de la novela a partir de diferentes encuentros y luchas con otros discursos que han sido hegemónicos sobre el cuerpo.

Por consiguiente, en la novela confluyen diferentes saberes sobre el cuerpo, los cuales han prevalecido a lo largo de la historia de occidente, como, por ejemplo, el entender al ser humano como un compuesto de alma y cuerpo (tradición que viene desde la antigua Grecia y continúa en el cristianismo), así como la aproximación al cuerpo desde su conservación y cuidado por parte del discurso médico. Estos discursos, desde el conocimiento, configuran la experiencia del cuerpo propio y del cuerpo como objeto. Es a partir de estas concepciones que los hombres se entienden a sí mismos como sujetos corpóreos $\mathrm{y}$, por lo tanto, forjan las maneras de ver y de relacionarse con los otros. Por lo anterior, podemos entender el cuerpo como un constructo discursivo; volviendo a Corbin (2005): “[e] 1 cuerpo es una ficción, un conjunto de representaciones mentales, una imagen inconsciente que se elabora, se disuelve, se reconstruye al hilo de la historia del sujeto, por mediación de los discursos sociales y de los sistemas simbólicos" (p. 17). Así pues, el cuerpo en La carne de René, como lo señala Corbin, es un efecto de los discursos y, por lo tanto, no hay manera de hacerse un cuerpo propio sin la mediación del discurso cárni$\mathrm{co}^{4}$.

Ahora bien, frente al término discurso, si bien ha sido definido por múltiples disciplinas y teóricos, Michel Foucault (1999) se aproxima a este desde la discusión sobre el poder, el conocimiento y la verdad, entendiéndolo como el medio y el lugar de lucha de esta triada5: "el discurso no es simplemente aquello que traduce las luchas o los sistemas de dominación, sino aquello por lo que, y por medio de lo cual se lucha, aquel poder del que quiere uno adueñarse" (p. 15).

Como señala Sara Mills (1997), el discurso para Foucault es más que un grupo de signos o textos: como él mismo lo plantea en la Arqueología del saber (1972), está constituido por un conjunto de "practices that systematically form the objects of which they speak" (p. 49). Según esto, Mills propone que los discursos producen algo más allá que tex- tos y no existen por sí solos; los discursos producen formas de pensamiento, ideas y conceptos que se forman en un contexto específico y que tiene un efecto sobre las formas de pensar y de actuar de los individuos.

En este sentido, el conocimiento es el resultado de una lucha de poder entre diversos conocimientos: "es necesario concebir el discurso como una violencia que se ejerce sobre las cosas" (Foucault, 1999, p. 53). Esos encuentros de diversos discursos sobre el cuerpo pasan por diferentes luchas que se evidencian en la novela a través de un mecanismo narrativo como la parodia. Así, por ejemplo, en el momento en que Ramón le revela a su hijo los secretos de la Causa, lo invita a su despacho secreto, el cual resulta ser un cuarto destinado a la tortura. Allí, René se encuentra con un cuadro:

Finalmente, sus ojos se posaron en un cuadro de grandes dimensiones, un óleo del martirio de san Sebastián. O al menos el pintor tomó como punto de partida dicho martirio, porque en el caso de este cuadro no se podría afirmar que fuera exactamen-

$4 \quad$ Para entender otras perspectivas sobre la relación entre cuerpo y literatura, sugiero revisar el artículo "La literatura como in-corporación: el cuerpo como proceso" de Pinzón Manrique (2014), en el que hace una aproximación fenomenológica a la cuestión.

5 Foucault propone que el discurso debe ser estudiado desde un método "crítico" y "genealógico", es decir, desde un análisis que se pregunte por las formas de control de los discursos y, asimismo, que logre poner de manifiesto cómo se forman. Este doble ejercicio de análisis es clave para dar cuenta de cómo se configura el discurso cárnico. 
te un martirio. La pintura presentaba a un hermoso joven, tal como lo había sido Sebastián, en actitud reposada, con la mirada perdida y una sonrisa enigmática. [...] San Sebastián sacaba las flechas de un carcaj y se las calvaba en el cuerpo. [...] René retrocedió espantado: era su cara. Este san Sebastián era René. (Piñera, 2000, pp. 27-28).

La pintura descrita utiliza la parodia ${ }^{6}$ como un mecanismo para lograr un nuevo significado. Es por medio de la alteración del texto original y su relación con el rostro de René, como lo señaló la cubana Madeline Cámara (2002) en "Inscripciones postmodernas a La carne de René", que René puede decodificar y entender ese nuevo significado: él será entregado a una causa, pero no a la del cristianismo, sino a la del chocolate, o mejor, a la de la carne para el servicio del dolor. Por lo tanto, san Sebastián representa el cuerpo sufriente, el cual se encarga de mostrarle a René su destino: educar su carne para entregarla al dolor. Así, estas parodias dentro de la novela se dan en un marco pedagógico, instructivo de una verdad, de un conocimiento que debe ser impuesto a la carne. La parodia, en esa medida, es fundamental para entender cómo la novela, al dislocar los significantes, logra llenar de nuevos significados a algunos elementos presentes en otros discursos, por lo que estos devienen distintos.

Dentro de las luchas discursivas que se dan en la novela, el discurso médico también se ve parodiado con el fin de redireccionar a René en las sendas del cuerpo para el dolor. Ramón realiza una intervención a un libro de anatomía que la señora Dalia de Pérez (quien entrega su carne al placer) le había regalado a René con la intención de seducirlo para poder tener relaciones sexuales con él. Dicho libro se titulaba "EL CUERPO HUMANO”. La señora Dalia de Pérez, muy hábil en su conquista, fue llenando de connotación sexual las figuras expuestas en el libro:

Sin hacerle caso, ella pasó la hoja. Esta vez la figura era femenina y, como la anterior, se presentaba en posición típicamente anatómica. Resultaba tan aséptica que, temerosa de que René comenzara a re- flexionar sobre las miserias de la carne, Dalia se dispuso a erotizar la 'frigidez' de la figura (Piñera, 2000, p. 45).

De este modo, la señora Dalia utiliza el libro de anatomía para mostrar que esos cuerpos cuidados e intactos, como el cuerpo virginal de René, pueden estar dispuestos para el placer. Dalia espera, así, despertar el deseo del placer en René, ya que esos cuerpos se oponían a los que él tanto temía y con los únicos que había tenido contacto: cuerpos llenos de llagas y heridas, cuerpos para el dolor.

Piñera logra articular el discurso médico moderno con el cuerpo para el placer, en la medida en que el primero se forja, desde el siglo XVI, como el estudio y cuidado del cuerpo. Este discurso surge con un interés marcado en la observación, análisis y descripción, los cuales ya eran los pilares de ciencias más avanzadas en sus métodos como la zoología y botánica. Pero la observación como método no solo se limitó a entender cómo el cuerpo funciona en tanto máquina biológica, sino, también, en estudiar la enfermedad, por lo que se gene-

$6 \quad$ Linda Hutcheon (1985), en su libro A Theory of Parody. The Teachings of Twentieth-Century Art Forms, afirma que la parodia en el siglo XX se complejiza y cobra gran importancia para diversos campos de la creación artística. La parodia, dice Hutcheon, procede a partir de la superposición de dos planos de sentido: un primer plano que parodia, y un segundo que es el parodiado. Ese segundo plano, el que contiene el intertexto parodiado, es el que permite que el primer plano, la creación nueva, tome un nuevo sentido y el lector pueda comprenderlo. Este mecanismo discursivo, en esa medida, necesita de una intervención del intertexto. Sin embargo, la parodia no necesariamente se da como una mera burla que realiza el texto visible al texto que subyace, sino que esta opera desde una "transcontextualización" de ese segundo plano. La parodia es repetición con distancia crítica. 
ró una preocupación al interior de la medicina frente a la esperanza de vida. Sin embargo, no es hasta el siglo XVIII que por diversos intereses políticos, los estados nacientes se empezaron a preocupar por la conservación de la vida, lo que implica el cuidado del cuerpo desde las buenas prácticas sanitarias y de higiene (Faure, 2005).

Por otro lado, en esta evolución de la medicina que comenzó en el siglo XVI, el dolor se torna uno de los temas que preocupan tanto a los estudiosos del cuerpo humano como a los filósofos y religiosos. Así, debido a la herencia religiosa, el dolor que produce la enfermedad fue visto como un don pero también como un castigo, por lo que este no debía ser cegado a partir de calmantes, sino que debía ser vivido y resistido. No obstante, en el siglo XIX, cuando la religión se ha empezado a separar de las ciencias, el dolor se puede abordar sin su connotación religiosa, desde la medicina y filosofía. La medicina entiende el dolor como un síntoma de la enfermedad, por lo que busca formas de intervenir a los pacientes sin dolor y de calmar su padecimiento. Las investigaciones con éter y opioides, permitieron que se avanzara hacia la creación de la anestesia y a los diferentes analgésicos y calmantes que desplazan el dolor de su significado espiritual, y lo convierten en un padecimiento que hay que tratar y evitar en el momento de intervenir el cuerpo, en especial en los procedimientos quirúrgicos.

En consecuencia, el discurso médico moderno configura un cuerpo que debe ser cuidado y preservado en su integridad, del cual también, gracias a los avances técnicos, se intenta alejar del dolor. Es por esto que la señora Dalia puede interpretar el libro de anatomía, que se inscribe en el discurso médico, para hacer una analogía entre esos cuerpos dispuestos para la observación y descripción; y el cuerpo, para el placer. Este, al igual que el configurado por el discurso médico, debe ser conservado y, en la medida de lo posible, alejado del dolor para entregarse a los goces de la carne, es decir, a la actividad erótica.

Sin embargo, Ramón interviene las imágenes de la siguiente manera: "[s]i el hombre aparecía en la misma posición, decenas de flechas se clavaban ahora en su carne, en tanto que la cara era del mismo René. Las manos, descansando sobre los muslos, sostenían una flecha vuelta hacia su propio cuerpo" (Piñera, 2000, p. 50). Esta parodia, que se da desde la modificación de las imágenes de los cuerpos del libro de anatomía, le permite a Ramón distanciarse de los fines de la carne dispuesta para el placer que abandera la señora Dalia, para redireccionar a René hacia la carne para el dolor. La parodia aquí opera desde la intervención de las imágenes construidas desde el discurso médico, las cuales se significan desde las intenciones de la señora Dalia. Al superponer el rostro de René a esos cuerpos y hacer que estos parezca que se están autoflagelando y esperando por ser heridos, se trasgrede el discurso que entiende el cuerpo desde su preservación, para oponer el cuerpo para el dolor al cuerpo para el placer. El primero, por medio de esa lucha discursiva, logra imponerse como única verdad que, según Ramón, René debe seguir:

Qué curioso: la señora Pérez resume su vida entera en el placer. [...] Este álbum, quién lo duda, es un hermoso regalo $[\ldots]$, no era el caso tirarlo por la borda a causa de sus placenteras figuras, cuando con un poco de cuidado quedaría lista para el servicio del dolor. (Piñera, 2000, p. 52).

Por lo tanto, se puede ver cómo el discurso cárnico se va configurando -desde la parodia- a partir de la lucha con otros saberes, que aquí se usan para generar oposición entre dos formas de darse a la carne. En consecuencia, esta nueva corporalidad va dibujando sus límites a través del encuentro y lucha con otros discursos.

El discurso de la carne para el dolor no solo se va formando a 
través de la oposición y lucha con otros discursos, sino que este mismo se va configurando como una pedagogía, es decir, como un conocimiento que además de enseñarse, modifica el objeto de su discurso y al que se dirige, es decir, al cuerpo propio. Por esta razón, esas iconografías intervenidas por Ramón, que se anclan en diversos discursos, "buscan hacer un poco de pedagogía" (Piñera, 2000, p. 53).

Hacia una pedagogía del dolor: trasgresión de la tradición mística y ascética cristiana

Desde el inicio de la novela, las referencias al cristianismo abundan: las parodias de la imagen de san Sebastián y a la incredulidad de santo Tomás, las comparaciones entre la carne de res colgada en la carnicería y la hostia consagrada, o la mención del martirio de santa Catalina de Siena demuestran la prevalencia e importancia del discurso cristiano para la construcción del discurso cárnico en este mundo piñeriano. Para Anderson (2002), en "El 'sermón pro-carne' de Virgilio Piñera: parodia de la iglesia Católica y negación de la espiritualidad en La carne de René", la esfera espiritual del individuo es negada en el universo que crea Piñera. La novela, así, se posiciona frente al discurso cristiano por medio de la parodia, con distancia crítica y diferenciación, ya que utiliza y disloca sus propios recursos y medios para configurar el discurso y el armazón institucional que lo sustenta, como es el caso de la escuela del dolor. De modo que, el cuerpo es lo que debe ser educado en el dolor, puesto que una vida sin sufrimiento, para personajes como Ramón o Cochón, no vale la pena. En ese sentido, a partir de la tensión entre el discurso cristiano y el discurso cárnico que empieza a emerger, se evidencia esa lucha entre conocimiento-poder que se da al interior de la novela, pugna que gesta una nueva carnalidad que se logra imponer como el discurso hegemónico.

René, dentro del camino pedagógico que le ha trazado Ramón para que lidere la Causa, debe internarse en una escuela que educa la carne para el servicio del dolor. Este programa de tres años evidencia cómo los cuerpos son un efecto del discurso, en este caso, de las prácticas educativas que se inscriben en el discurso cárnico, las cuales se encargan de instaurar y "recordar" aquellos hábitos y costumbres que se consideran "naturales" en los cuerpos.

De este modo, esa institución tiene como único objetivo la carne, por lo que es necesario cumplir con la máxima norma: “SUFRIR EN SILENCIO" (Piñera, 2000, p. 57). Este lema, encabezado por Mármolo (el director de la escuela), es una de las condiciones básicas para el aprendizaje de la carne para el servicio del dolor. El silencio no solo es fundamental para esta escuela, también ha sido una de las normas más importantes para la formación espiritual. Por ejemplo, las primeras congregaciones monásticas que eligieron la vida cenobítica (el cultivo espiritual en comunidad) fueron adoptando la regla de San Benito que se proclamó en 529 d.C. Entre las virtudes principales que dictamina la regla-como la obediencia y la humildad- estaba el silencio (Quintana, 2012), por lo que muchos de estos recintos monásticos confinaban a los monjes en celdas individuales para que pudieran propiciar la comunión con Dios por medio de la oración y los coloquios con Jesucristo.

Para lograr la unión mística con Dios, las prácticas ascéticas o los llamados ejercicios espirituales se configuran a partir de los evangelios y de la tradición filosófica, la cual se preocupaba por el cultivo del bien, del ser verdadero que dista del yo sensible. Según Hadot (2006), la filosofía griega ha de entenderse como una práctica, como unos ejercicios que propiciaban un conocimiento de sí mismo a partir del apaciguamiento de las pasiones y del redireccionamiento de ciertas formas "incorrectas" de vida. Ahora, la vida mística, que encierra las prácticas ascéticas, también debe entenderse como una búsqueda de un conocimiento que solo es 
posible encontrar a través de la experiencia. Esta práctica gira en torno a la vida de Cristo, a la imitación de su vida y, sobre todo, se centra en la Pasión. En ese sentido, a partir de prácticas como el martirio del cuerpo y la penitencia, se podrá lograr la vida verdadera y eterna que dista de lo corpóreo ${ }^{7}$.

De ahí que el cuerpo sea el "principal obstáculo, 'el mayor enemigo' y el medio para acompañar al Redentor: el cuerpo que hay que vencer, el cuerpo vector de una operación sacrificial" (Gélis, 2005, p. 54), para lograr la unión con lo inmutable y eterno. Por eso, como lo expuso san Agustín (1983), el cuerpo debe ser subyugado por el alma: “¿Para qué, pervirtiendo el orden que debe haber entre el cuerpo y el espíritu, sigues tú a tu carne? Ella es la que convertida y reducida a buen orden te debe seguir a ti" (IV 17). Así, todas las pasiones y deseos de la carne deben ser aplacadas y silenciadas para el encuentro místico.

En La carne de René, las prácticas del dolor son modeladas por medio de la escuela. Al igual que en los monasterios medievales, la escuela del dolor no solo normaliza unas prácticas pedagógicas, sino que regula el discurso y permite -como toda institución educativa- enunciar qué es verdad y, por medio del poder que se ejerce desde el conocimiento, configurar la carne para el servicio del dolor, el cual es el propósito de esa institución.

Así, René, al momento de ingresar a la escuela, tiene el primero de varios encuentros con parodias y trasgresiones a la iconografía cristiana. Al entrar a su habitación, se encuentra con un Cristo crucificado que posee su rostro:

Ante sus ojos apareció la consumada reproducción de sí mismo, en el trance de la crucifixión inspirada en la de Cristo, el escultor había introducido una modificación capital: en vez de la patética y angustiada faz de Jesús, la cara de René en yeso se ofrecía, no caída sobre el pecho, sino erguida, y la boca mostraba la risa de una persona satisfecha. Podría afirmarse que acaba de oír un chiste. $O$ también, que era la cara jubilosa del atleta vencedor. (Piñera, 2000, p. 61).

El doble -nombre que Cochón, el predicador de la escuela, le dio a estas esculturas- además de tener un propósito formativo, cumple con una función dentro de la institución de la carne: entronar el cuerpo sufriente de Cristo como centro de sentido para entregar la carne al servicio del dolor. Por tanto, este se significa diferente para sus propios fines por medio de la parodia del discurso cristiano.

Gélis (2005) señala que la iglesia cristiana se fundamentó en el Dios hecho carne, el cual:

[...] ofrece su persona a la vindicación pública $\mathrm{y}$ su cuerpo a la persecución para salvar a los pecadores. Desde la Encarnación hasta la Resurrección, se trata por tanto del cuerpo, del cuerpo de un Dios de amor que acepta sacrificarse antes de volver al Cielo a través de esta última secuencia que es la Ascensión. (p. 30).

Así pues, esta parodia que realiza el doble del cuerpo de Cristo, logra dislocar el significado que le otorga la religión cristiana. Para eso, la parodia opera desde dos figuras retóricas: la ironía y la analogía entre el discurso cristiano y el cárnico.

Por medio de la ironía, se trasgrede el significado que se le ha otorgado a la Pasión al cambiar el rostro del Cristo sufriente por el de René sonriendo ante el vituperio y maltrato. Al disponer

\footnotetext{
El cuerpo como extensión para llegar a la comunión con lo divino ha estado presente constantemente en la tradición poética de occidente. Desde santa Teresa de Jesús, pasando por poetas como Novalis, hasta escritores contemporáneos como Viel Temperley, como lo sugiere Enzo Cárcano (2014).
} 
el cuerpo al sacrificio, no se busca ninguna redención, puesto que no hay nada que redimir ni ningún cuerpo que purgar para la purificación del alma, ya que el rostro se nos muestra satisfecho ante el dolor de haber entregado sus carnes al martirio. A través de este tropo, el discurso cárnico toma distancia del discurso cristiano al mostrar un cuerpo que se entrega al dolor por solo tener la complacencia de darse al sufrimiento.

Por otro lado, el doble, gracias a la analogía en la parodia entre el discurso cárnico y el discurso cristiano, logra apropiarse del Cristo sufriente como centro de su discurso, lo que hace que ambos discursos se signifiquen desde esa imagen. Sin embargo, como en toda analogía, hay puntos de encuentro y de diferencia. Para el cristianismo, Jesús es el modelo de vida, es aquel al que hay que aspirar, no solo por sus obras, sino porque al darse en sacrificio se desprende de su singularidad como hombre y se vuelve uno con Dios, con lo inmutable, así como lo señala Bataille (2007):

Antes que se le dé la muerte, estaba encerrado en la particularidad individual. [...] Pero, en la muerte, ese ser es llevado de nuevo a la continuidad del ser, a la ausencia de particularidad. Esa acción violenta, que desprovee a la víctima de su carácter limitado y le otorga el carácter de lo ilimitado y de lo infinito pertenecientes a la esfera sagrada, es querida por su consecuencia profunda. (p. 95).

Gracias a esta interpretación de la Pasión, la vida mística y las prácticas ascéticas cobran sentido. Ahora, en el discurso cárnico, el cuerpo de la Pasión se usa desde la representación que el doble hace del cuerpo René, es decir, él debe tomar como modelo a seguir su propia carne sufriente, la cual, al final de la formación que se da en la escuela, debe afrontar el sufrimiento con alegría y satisfacción. En consecuencia, cada estudiante formado en esta escuela debe seguir su propia carne, por lo que el cuerpo sufriente, sin importar el rostro, es lo que está en el centro de este discurso, es el lugar de culto. Así mismo, el deseo de trascendencia y pérdida de la individualidad al momento de perder el cuerpo (el cual es la base del deseo místico que proviene desde Plotino), también es una de las finalidades de la práctica de la carne para el servicio del dolor, pero esta se da en condiciones diferentes. Este discurso no busca una unión con el Uno, pero sí pretende una pérdida de toda individualidad, ya que el cuerpo lacerado queda reducido a mera carne maltratada, la cual es equiparable a cualquier otra porque finalmente solo es carne.
Ejercitando la carne: ruptura de la dualidad alma-cuerpo

René debe asistir a las clases que se imparten en la escuela para el cultivo de la carne, las cuales se rigen por el lema de la escuela: sufrir en silencio. Por lo tanto, los neófitos, como lo dispone Mármolo, si no logran contener sus gritos por el dolor infringido, la escuela se encargará de fabricar el silencio. Por ello, el uso del bozal se hace necesario para que en los ejercicios de exposición al dolor los estudiantes no puedan expresar el sufrimiento:

[u]stedes me dirán: ¿por qué se nos amordaza si se debe dar rienda suelta al dolor? Ponemos mordazas porque estamos por el dolor concentrado y reconcentrado. La boca que se abre para gritar desaloja automáticamente una preciosa cantidad de dolor (Piñera, 2000, p. 77).

El dolor, entonces, debe ser direccionado y debe tener un propósito dentro de la formación de estos cuerpos. Por un lado, el bozal funciona como una forma de animalizar los cuerpos, lo que permite que se empiece un proceso de pérdida de subjetividad que es uno de los fines de la escuela, y uno de los pilares del discurso cárnico: "le habían puesto al alumno un bozal, y causaba el efecto de una animal acorralado. Pronto se 
generalizó el paso de hombre al estado de bestia" (Piñera, 2000, p. 69). Por otro lado, este permite que exista una moderación en el suministro y en la forma de asimilar el dolor infringido, ya que se busca que el dolor sea gradual en los estudiantes y que estos sepan que este debe ser el que los domina, no al contrario. Es por esto que deben aprender a sufrir los mayores martirios y espantos posibles, y mantener el silencio, no como una forma de vencer al dolor, sino como una manera de resistirlo y de vivirlo. Como lo recalca Mármolo:

[...] les advierto que no se equivoquen creyendo que rinden una prueba de virilidad. No, ya he hablado aquí de que el honor, entre nosotros, sobra. Saber que se sufre, que los dolores son espantosos, que se está a dos dedos de pedir tregua $\mathrm{y}$, sin embargo, no cejar, constituye el abc del sufriente (Piñera, 2000, p. 77).

Ahora bien, para que el discurso cárnico pueda configurar un cuerpo para el dolor, y que los sujetos no se entiendan como seres que pueden trascender su propia carnalidad, este discurso debe luchar contra toda una tradición que divide a los sujetos en dos sustancias: alma y cuerpo. Como se expuso, esta tradición viene desde la filosofía antigua y se acentúa en la imagen del Cristo sufriente que toman los padres de la iglesia como san Agustín. Por ejemplo, este santo, quien bebe del neoplatonismo, considera que el alma nos acerca a Dios, por lo que es necesario distinguir entre ambas sustancias (alma y cuerpo), y conocer cuál es la que le permite al hombre entrar en comunión con Dios. Después de un largo camino recorrido, como lo manifiesta en sus Confesiones (1983), se percata que Dios habita el alma, de modo que para tener una vida bienaventurada es necesario el cultivo de esta, procurando la mesura de los apetitos y deseos de la carne: "pero como la carne tiene unos deseos contrarios al espíritu, y éste los tiene también opuestos a la carne, no pudiendo uno y otro hacer lo que entrambos quieren, vienen a dar y caer en lo que pueden" (X 33). Por lo tanto, dicha tradición considera que el cuerpo debe ser aplacado para poder purificar el alma de los deseos de la carne, y así, lograr entrar en gracia con Dios.

Así pues, Mármolo, como lo hace desde la bienvenida que la da a René a la escuela, debe estar repitiendo constantemente que la escuela busca el cultivo del cuerpo y, por lo tanto, niega rotundamente algo inasible como el espíritu:

¿Qué cosa era eso del espíritu? ¿Lo sabía alguien? ¿Alguien lo había tocado? Si por espíritu se entendía el cuerpo, la escuela que él dirigía era altamente espiritual [...] un cuerpo privado del dolor no es un cuerpo sino una piedra. A mayor capacidad de dolor mayor vitalidad. (Piñera, 2000, p. 68).

A través de la parodia de los ejercicios espirituales y a las prácticas ascéticas, el discurso cárnico lucha y se impone al discurso cristiano, ya que esta otra corporalidad no busca ser una alternativa alejada de la tradición, sino que usa sus mismos medios y métodos para transgredirla, vaciarla de sus significados, y poder proclamar la discursividad de la carne.

De este modo, por ejemplo, san Ignacio de Loyola (1963), en un manual titulado Ejercicios espirituales, propone mecanismos para dominar y purificar el cuerpo para el encuentro del alma con Dios. San Ignacio, como en el mismo título de los Ejercicios lo propone, "Exercicios espirituales para vencer a sí mismo y ordenar su vida, sin determinarse por afección alguna que desordenada sea", debe buscar el dominio del cuerpo, y con este, las pasiones de la carne. San Ignacio aconseja que la carne debe ser maltratada para dichos propósitos. En las adiciones para hacer mejor los ejercicios para la primera semana, el santo, en la décima adición, aconseja que debe haber un dolor interno y externo 
por los pecados. El externo es el castigo de la carne: "es a saber, dándole dolor sensible, el qual se da trayendo cilicios o sogas o barras de hierro sobre las carnes, flagelándose o llagándose, y otras maneras de asperezas" (p. 85). Por lo anterior, el infringir dolor está relacionado con vencer el cuerpo y a los deseos de la carne que conducen al pecado. Así mismo, por medio del dolor, el hombre logra hacer un reconocimiento de los padecimientos que sufrió Cristo en la Pasión.

Al retomar las palabras de Mármolo, en las que interpreta los ejercicios como métodos de enseñanza necesarios para que la carne pueda darse al dolor y, de ese modo, lograr entregarse a la vida plenamente, se puede ver cómo esta pedagogía busca formar seres que puedan tener tal manejo de sus carnes que puedan alcanzar, a través del dolor, la máxima vitalidad posible. Como él mismo lo señala, la capacidad de resistir el dolor es directamente proporcional a la vitalidad ganada. De esta manera, los ejercicios niegan la dualidad alma-cuerpo, no solo al sostener que lo que llamamos espíritu es inasible, carece de materialidad y, por lo tanto, es inexistente; sino que al momento de infringir dolor a la carne, a pesar de usar los mismos métodos de la ascética cristiana, se distancia de sus objetivos, ya que el dolor no busca anular y negar el cuerpo, todo lo con- trario, reafirma la carne como única condición de la vida, le devuelve su carácter sensible y la llena de vitalidad. En el momento que no haya dolor, que la carne no sienta, no hay vida.

Esta forma de entender las diversas prácticas ascéticas ya estaba presente en La genealogía de la moral de Nietzsche (2013), en el tercer tratado "¿Qué significan los ideales ascéticos?". Nietzsche ve en el dolor infringido a los cuerpos, por parte de los ascetas, una exaltación de la vida material y sensible. Según Nietzsche, el ideal ascético y sus prácticas buscan eliminar el sufrimiento de la vida de los hombres. El sacerdote asceta interpretó y redireccionó el sufrimiento hacia la culpa del pecador. Entonces, la culpa por los pecados es la causa del dolor en los hombres, la cual debe ser redimida por medio de diferentes vías, como la no culpable y la culpable. Esta última usa la penitencia como forma de tratar y "sanar" el sufrimiento. Por ello, el asceta busca la manera de sanar ese desplacer, debido a ese redireccionamiento del sufrimiento hacia la culpa, por medio de la negación y deprecio de la vida sensual desde el castigo del cuerpo. Sin embargo, el filósofo alemán plantea que el rechazo a la vida es una voluntad de llegar a la nada, "así, esa nada, [fuera] llamada Dios" (p. 196), por lo que esa negación es, ante todo, una voluntad por adueñarse de las condiciones básicas de la vida, es decir, de la vitalidad fisiológica:

Una vida ascética es una autocontradicción: en ella domina un resentimiento sin igual, el resentimiento de un insaciado instinto y voluntad de poder que quisiera enseñorearse, no de algo existente en la vida, sino de la vida misma, de sus más hondas, fuertes, radicales condiciones. (pp. 172-173).

De este modo, Nietzsche analizó esa paradoja que se da en el intento por negar la vida, de la penitencia dolorosa como forma de acabar con el desplacer y de controlar la corporalidad, puesto que, a través de las prácticas ascéticas que llevan al castigo del cuerpo, se produce una afirmación de los presupuestos fundamentales de la vida, de la corporalidad como condición básica para la existencia. Así pues, por ejemplo, el dolor que se produce san Ignacio de Loyola no logra negar la existencia y redimir la culpa, al contrario, afirma la vida y lo ata al cuerpo que tanto quisiera anular.

Al igual que ese análisis del ideal ascético que realizó Nietzsche, en la novela, el dolor infringido en los ejercicios de la escuela, pone en evidencia esa paradoja de las prácticas ascéticas cristianas, pues al intentar negar el cuerpo y redimir la culpa por los pecados por medio del castigo, no se niega el cuerpo para la redención 
del alma, ya que el mismo martirio reafirma la existencia de la extensión corpórea. Así mismo, según el planteamiento de este filósofo, el dolor presenta otra paradoja: hay un deseo y, por lo tanto, un goce en el mismo, lo que conlleva a un disfrute del cuerpo que es lo que supuestamente se intenta callar. Si seguimos la crítica de Nietzsche, en la novela, como lo señala Mármolo y Ramón, los cuerpos se educan para poder vivir el dolor, para que no comprendan la carne sin darla a la flagelación, a la herida, por lo que debe existir un deseo por esta en la que los cuerpos se gozan a sí mismos en el dolor, al punto de lograr esa sonrisa impresa en el doble.

Por lo tanto, el discurso cárnico se configura desde la lucha entre poder-conocimiento que se da entre los discursos. Por medio de una institución como la escuela, este discurso logra imponer su hegemonía en el conocimiento que se dispone a enseñar. En este sentido, la ruptura entre alma y cuerpo cobra peso solo a partir de la imposición que tiene el discurso cárnico sobre el cristiano, lo cual se logra a partir de la parodia y apropiación del cuerpo sufriente de Cristo.

Las resistencias fallidas de René

A pesar de todo este aparato institucional, René, en la escuela y por fuera de esta, se resiste a unas formas de poder que se ejercen desde un saber, el cual busca disciplinar y configurarlo para el servicio del dolor. Este conocimiento sobre la carne, como se analizó, surge desde una lucha entre poder-conocimiento. En el caso del discurso cárnico, el saber sobre la carne se configura desde una confrontación con otros conocimientos sobre el cuerpo, por lo que esa verdad necesariamente nace desde un ejercicio de poder por medio del discurso y en los discursos mismos. En ese sentido, los cuerpos, o mejor, la carne es el centro de acción de esas formas de poder. De esta manera, cuando la escuela o la Causa ejercen su poder sobre la carne de René, se está dando la carne a un nuevo conocimiento desde el que se busca configurarla, ya que no es posible entender el poder sin que se cree un saber, tal como lo señala Foucault (1984):

[P]oder y saber se implican directamente el uno al otro; no existe relación de poder sin constitución correlativa de un campo de saber, ni de saber que no suponga y no constituya al mismo tiempo unas relaciones de poder. [...] En suma, no es la actividad del sujeto de conocimiento lo que produciría un saber, útil o reacio al poder, sino que el poder-saber, los procesos y las luchas que lo atraviesan y que lo constituyen, son los que determinan las formas, así como también los dominios posibles del conocimiento. (pp. 34-35).

Así, René logra resistir a dicho conocimiento sobre la carne, a través del pensamiento. En su estancia en la escuela, las acciones de resistencia por parte de René fueron una constante, por lo que Mármolo y Cochón necesitaron de estrategias pedagógicas que propiciaran el encauzamiento de René en la aceptación de su condición como sujeto cárnico:

¡Atención, René! ¡René, René, una vez más: ¡Atención! ¿Podemos comenzar? Entonces, ¡atención! (Pausa larga.) ¿Por qué no quiere? ¿No quiere porque no quiere queriendo o quiere porque quiere no querer? ¿Quiere queriendo o quiere no queriendo? ¿Cómo quiere? (Ruidos.) ¿Quiere que cesen los ruidos? No, usted es incapaz de querer, usted lo ha dicho, usted no quiere. Diga con nosotros: yo quiero, tú quieres, él quiere, nosotros queremos, vosotros queréis, ellos quieren. Dígalo ahora sin los pronombres: quiero, quieres, quiere, queremos, queréis, quieren. Repita, René, repita más rápido $[. .$.$] No, René,$ no pienses; nunca piense; sólo quiere, quiera, quiera. (Piñera, 2000, p. 87). 
La repetición de ese mensaje tiene un objetivo preciso: silenciar la mente de René para que reconozca que es carne $\mathrm{y}$ nada más. Hacer que René no piense es apremiante porque la escuela ve en su pensamiento un peligro para el objetivo de la formación. Para la escuela, la carne no puede pensarse a sí misma, simplemente debe darse a lo sensitivo y pedir por el dolor. Además de eso, si la carne se piensa implica que René se comprende como un ser que se hace desde la mente y no desde la carne, por lo que ese acto es lo que le permite resistirse a entregar su carne a las enseñanzas de la escuela:

Una mañana [René] manifestó a Pedro que no quería levantarse, y mucho menos presentarse en el aula. Sacado a viva fuerza del cuarto, se negó de plano en el aula a efectuar el ejercicio señalado, y hasta tuvo la osadía de arengar a sus compañeros [...] Con René, todo era distinto. Se trataba de alguien que no se compadecía de su carne como tal, sino que protestaba por el ultraje infligido. (Piñera, 2000, pp. 88-91).

Mármolo, advertido de la situación, no encuentra otra salida que contarle a Ramón lo que sucede con la carne de su hijo: "[s]u carne no es del todo carne; tiene adentro el demonio del pensamiento [...] Es una carne que se permite pensar sobre sí misma, a diferencia de las otras que se encuentran en la escuela" (Piñera, 2000, p. 120). De este modo, se podría afirmar que René -desde acciones como el alejarse de la carne, hasta intentar ser un descarnado- es un ser que desde el pensamiento intenta crear su individualidad fuera del orden carnal, ya que el pensar sobre su mundo, sobre el dolor, como lo señala Rita Molinero (2002), no le permiten integrase al mundo y disfrutar de la crueldad que lo circunda.

Por lo anterior, pensar sobre su cuerpo es el único camino que René tiene para hacerse una subjetividad distinta a la impuesta por el aparato sociopolítico. Esa individualidad que René intenta construir se da desde la escritura, específicamente cuando inicia sus estudios en taquigrafía y mecanografía una vez sale de la escuela y se va de la casa de sus padres. De este modo, René, una vez más escindido entre mente y carne, superpone la primera a la segunda, lo que le permite intentar resistir al asedio de la Causa.

Sin embargo, es tal asedio que sufre René por parte de la Causa, que la facultad de pensar sobre su carne lo lleva a sucumbir ante la verdad impuesta por el discurso cárnico: "[u]n buen día René tuvo la comprobación definitiva de que estaba hecho de carne. Fue preciso un año entero y la sucesión de diver- sas experiencias que culminaron en una memorable tarde del mes de junio" (Piñera, 2000, p. 211). Finalmente, René, por más ahínco que haya puesto en su resistencia, no puede huir de la verdad: es un ser hecho de carne. El discurso cárnico cobra sentido en él y lo convierte en un sujeto de la Causa dispuesto a dar su carne al dolor. Como lo señala Antón Arrufat (2012):

René, [...] sistemáticamente y a ratos dolorosamente, se propone apartarse de la carne, a la que está sin embargo, según el sentido de la novela, condenado. Toda su acción desde el primer capítulo hasta el último, consiste solamente en huir. Huida patética y semejante a una apuesta metafísica, pues paso a paso comprende con horror que tal lucha es imposible: nunca podrá escapar de su propio cuerpo. (p. 49).

Así pues, la novela pone en evidencia a través de instituciones como la escuela y la Causa, cómo los cuerpos no pueden escapar de las relaciones de poder -ya sean educativas, políticas o normativas- las cuales les imponen un lugar y un fin al servicio del engranaje social:

[E]l cuerpo está también directamente inmerso en un campo político; las relaciones de poder operan 
sobre él una presa inmediata; lo cercan, lo marcan, lo doman, lo someten a suplicio, lo fuerzan a unos trabajos, lo obligan a unas ceremonias, exigen de él unos signos. Este cerco político del cuerpo va unido, de acuerdo con unas relaciones complejas y recíprocas, a la utilización económica del cuerpo; el cuerpo, en una buena parte, está imbuido de relaciones de poder $\mathrm{y}$ de dominación, como fuerza de producción, pero en cambio, su constitución como fuerza de trabajo sólo es posible si se halla prendido en un sistema de sujeción. (Foucault, 1984, pp. 32-33).

En la novela, las normas sociales, el legado familiar, junto a la formación impuesta por la escuela para servirle a la Causa, forjan carnes sujetas a un discurso del que, al parecer, no es posible escapar, ya que todos los miembros e instituciones de esta sociedad ejercen su poder hacia los sujetos a través de este discurso hegemónico sobre la carne.

\section{Consideraciones finales}

Luego de este análisis de La carne de René, en el que se estudió la obra desde el discurso como lugar donde se dan las luchas entre poder-conocimiento, se pudo ver cómo se configura el discurso cárnico en la novela, el cual ope- ra sobre la carne y el mundo. El discurso de la carne se delimita a partir de ciertas parodias que la novela realiza a discursos hegemónicos sobre el cuerpo, como el discurso médico, el cristiano y la dualidad alma-cuerpo. Estas parodias funcionan como mecanismos discursivos que permiten que se dé la lucha entre poder-conocimiento -que señala Foucault- a partir de la distancia que se genera entre el texto parodiado y el que parodia, debido al uso de figuras retóricas como la ironía y el símil, como, por ejemplo, en la parodia del cuerpo sufriente de Cristo en la escuela. Así, a través de esa lucha se logró entender cómo el discurso cárnico se impone como el discurso hegemónico en la novela.

De esta manera, Piñera pone de manifiesto cómo los discursos y el entramado social por los que estos circulan son mecanismos que sirven para la dominación de los cuerpos y, por lo tanto, de la vida, al punto que se podría pensar que para el escritor, como lo plantea en Discurso a mi cuerpo (Piñera, 1990) y como se evidencia en esta novela, el cuerpo no es algo que nos pertenezca. Así, a partir de la construcción de un discurso hegemónico, la obra logra mostrar -desde la parodiacómo los discursos, sus saberes, y las instituciones que los sostienen, ya sea la escuela, el sistema político, social, religioso o jurídico, ejercen un poder sobre los cuerpos, sobre la vida, al crear leyes, conocimientos y maneras que establecen las formas de relacionarnos con nosotros mismos y con los otros. En consecuencia, los discursos crean individualidades dispuestas al servicio de las instituciones o, por qué no, de un aparato estatal.

En conclusión, puedo afirmar que en este mundo piñeriano es tal la fuerza del discurso que no hay una manera efectiva de escapar y de hacerse una subjetividad por fuera de este, puesto que, incluso, la muerte hace parte del dominio del discurso cárnico. De ahí que, los intentos de René por construirse una individualidad por fuera de esta discursividad son intentos fallidos, ya que el poder que las instituciones ejercen desde el conocimiento de la carne no permite crear maneras efectivas de resistencia, pues siempre se vuelve a caer en la carne. Como lo plantea Gasparini (2002), es difícil responder sobre la ética de la libertad en una obra como esta, en la que el personaje solo puede escapar repetidas veces y falla, pues, al parecer, es imposible huir de la carne como único modo de existencia. René, en este caso, estaría negando la posibilidad de libertad. Así pues, a pesar de que René reflexiona sobre su carne, no consigue refutar la verdad base sobre la que reposa este sistema: somos seres cárnicos, ya que sin carne no hay vida posible. De este modo, no hay una manera de hacerse otras formas de vida que estén más allá de la carne, puesto que solo se es carne y nada más. 


\section{Referencias}

Agustín, S. (1983). Confesiones. Madrid: Espasa Calpe.

Anderson, T. F (2002). El 'sermón pro-carne' de Virgilio Piñera: parodia de la Iglesia Católica y negación de la espiritualidad en La carne de René. En R. Molinero (ed.), Virgilio Piñera: la memoria del cuerpo (pp. 341-362). San Juan: Editorial Plaza Mayor.

Arenas, R. (2002). La isla con todas sus cucarachas. En R. Molinero (ed.), Virgilio Piñera: la memoria del cuerpo (pp. 29-48). San Juan: Editorial Plaza Mayor.

Arrufat, A. (2012). Virgilio Piñera: entre él y yo. La Habana: Ediciones Unión.

Bataille, G. (2007). El erotismo. Barcelona: Tusquets editores.

Brioso, J. (2007). La carne de René o el aprendizaje de lo literal. Revista iberoamericana, 218, 29-49.

Cámara, M. (2002). Inscripciones postmodernas en La carne de René. En R. Molinero (ed.), Virgilio Piñera: la memoria del cuerpo (pp. 215-225). San Juan: Editorial Plaza Mayor.

Cárcano, E. (2014). El cuerpo como via mystica en algunos textos de Blake y de Viel Temperley. La Palabra, (25), 81-92. doi: https://doi.org/10.19053/01218530.2873

Corbin, A., Courtine, J., \& Vigarello, G. (2005). Historia del cuerpo. Madrid: Tauros.

De Loyola, S. I. (1963). Obras completas de San Ignacio de Loyola. Madrid: Biblioteca de Autores Cristianos.

Faure, O. (2005). La mirada de los médicos. En A. Corbin, J. Courtine y G. Vigarello (comps.), Historia del cuerpo (pp. 23-56). Madrid: Tauros.

Foucault. M. (1972). The Archeology of Knowledge. New York: Pantheon Books.

Foucault, M. (1984). Vigilar y castigar. México D.F.: Siglo XXI editores.

Foucault, M. (1999). El orden del discurso. Barcelona: Tusquets editores.

Gasparini, P. (2002). Carne fachera (sobre La carne de René, Ferdydurke y Paradiso). En R. Molinero (ed.), Virgilio Piñera: la memoria del cuerpo (pp. 289- 303). San Juan: Editorial Plaza Mayor.

Gélis, J. (2005). El cuerpo, la iglesia y lo sagrado. En A. Corbin, J. Courtine y G. Vigarello (comps.), Historia del cuerpo (pp. 27-104). Madrid: Tauros.

Hadot, P. (2006). Ejercicios espirituales y filosofia antigua. Madrid: Ediciones Siruela. 
Hutcheon, L. (1985). A Theory of Parody: the theachings of twentieth-century art forms. New York: Methuen.

Le Breton, D. (2002). La sociología del cuerpo. Buenos Aires: Claves-Dominios.

Milda, Ž. (2015). “¿Qué tal? ¿Virgilio?”: apuntes sobre la relación intelectual entre Virgilio Piñera y Witold Gombrowicz. Cuadernos Americanos, (153), 67-85.

Mills, S. (2001). Discourse. New York: Routledge.

Molinero, R. (2002). Esquivando flechas, resistiendo furias: el arte de la fuga en Pequeñas maniobras. En R. Molinero (ed.), Virgilio Piñera: la memoria del cuerpo (pp. 323 -340). San Juan: Editorial Plaza Mayor.

Nietzsche, F. (2013). La genealogía de la moral. Madrid: Alianza editorial.

Pinzón Manrique, H. (2014). La literatura como in-corporación: el cuerpo como proceso. La Palabra, (24), 91-97. doi: https://doi.org/10.19053/01218530.2504

Piñera, V. (1990). Discurso a mi cuerpo. Unión,10 (33), 35-36.

Piñera, V. (2000). La carne de René. Barcelona: Tusquets editores.

Quintana, J. (2012). Historias de la ascética y mística cristianas. Barcelona: AEAU.

Quintero Herencia, J. (2000). Virgilio Piñera: los modos de la carne. En D. Balderston (ed.), Sexualidad y nación (pp. 111-129). Pittsburgh: Universidad de Pittsburgh. 